\title{
The novice MP: The experience of the newly elected in Iceland
}

\author{
Stefanía Óskarsdóttir, Associate Professor, Faculty of Political Science, \\ University of Iceland \\ Ómar H. Kristmundsson, Professor, Faculty of Political Science, University \\ of Iceland
}

\begin{abstract}
The study is intended to provide novel insights into the adaptation of new members of parliament to a working environment that differs in many ways from more traditional workplaces. The study is based on semi-structured interviews with 16 first-term members of the Icelandic parliament, the Althingi, after two years' experience following their election in 2013. The findings show that learning to become active members of parliament is primarily an informal and disorganised process driven by the newcomers themselves. Little formal on-the-job training is available. Two years into their term, the interviewees felt they were still learning and adapting to the rules and norms. New MPs' performance seems to depend on several factors, including how active they are in the learning process and how successfully they manage to build relationships with colleagues and find informal mentors, who in some cases belong to different political parties. The data limits the inclusion of contextual factors potentially influencing the MPs socialisation process.
\end{abstract}

Keywords: Icelandic MPs; Althingi; professional job competence; organisational socialisation.

\section{Introduction}

How does a new member of parliament (MP) adjust to the job? This is an important challenge regardless of the organisation the newcomer enters; how to adjust to the new working environment and learn the behaviours, attitudes and skills necessary to function

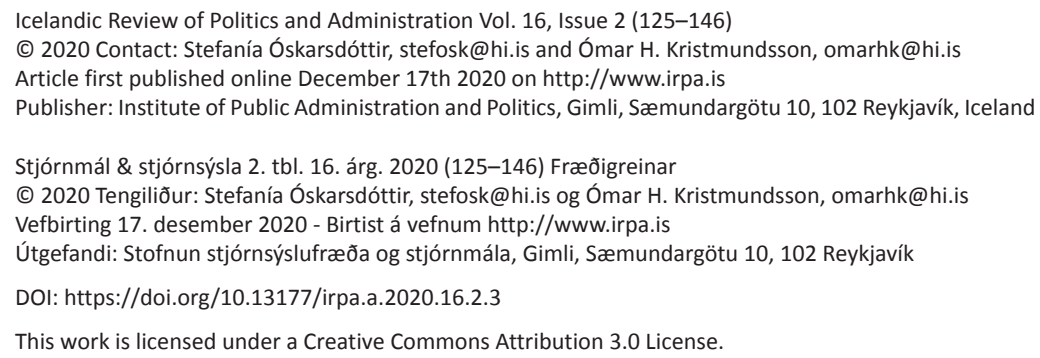




\section{STJÓRNSÝSLA}

effectively within the organisation (Bauer et al. 1998; Bauer et al. 2007). This adjustment process, known as organisational socialisation (OS), is defined as the transition from a "state of certainty to uncertainty; from knowing to not knowing; from the familiar to the unfamiliar" (Van Maanen \& Schein 1977, 16). Depending on the job and the organisation, the process can range from "a relatively quick, self-guided, trial-and-error process to a far more elaborate one, requiring a lengthy preparation period of education and training followed by an equally drawn out period of official apprenticeship" (Van Maanen \& Schein 1977, 212).

Several models of organisational socialisation, describing elements and processes of OS, have been created (Jones 1986; Saks 2007; Cooper-Thomas \& Anderson 2006). The process of transition can be divided into different phases. Feldman (1976) identifies three. The first is when the newcomer prepares to enter the organisation (in Feldman's term "anticipatory socialisation"). The goal for the newcomer is to gain an overview of the job and the organisation. The second phase ("accommodation") takes place when the newcomer starts the transition period within the organisation, starts to learn the job and how the organisation is operated and begins to gain acceptance from his or her co-workers. The third phase, "role management", follows the accommodation stage for newcomers and focuses on the learning process and adjustments required to become a fully accepted member of the organisation. It adds detail and clarity to learning from previous stages.

Little research has focused on how individuals who are new to less traditional work roles, such as employment in parliament, understand what is expected of them and/ or how they learn to navigate their new working environments and perform their roles. One of the few is Rush and Giddings' comprehensive study of organisational socialisation in the UK parliament in the 1990s. According to the authors, parliamentary socialisation consists of three core components: agents, mechanisms, and processes (Rush \& Giddings 2011). Agents include, among others, the parliamentary party, standing committees, parliament authorities, and other members of parliament. In addition, there are agents outside the parliament, such as party colleagues, pressure groups and the media. The mechanisms include formal induction programs provided either by the party or the parliament administration. They also involve various kinds of informal advice given by the parliamentary staff, learning by observation and imitation of senior MPs considered to have the required experience necessary to become effective MPs (pp. 56-57). Agents are involved in three types of socialisation processes, including functional socialisation (learning the rules and procedures), attitudinal socialisation (adapting their attitudes to the legislative norms) and behavioural socialisation (adapting their behaviour to the rules and norms). According to Rush and Giddens, some contextual factors, including MPs' parliamentary roles, which are discussed later in the article, affect all three socialisation processes.

To study the socialisation of new MPs, 16 semi-structured interviews were taken with first-term members of the Icelandic parliament two years after they took office in 2013. Information was collected on how they adapted to their new role as MPs. 
The focus was on their preparation for the new role, engagement in the first months, and finally, their assessment of their first two years in office. Difficulties encountered by the interviewees in learning the ropes as MPs, and how they dealt with them, were explored. Feldman's adjustment stage approach and Rush and Giddens' parliamentary socialisation model were applied as a framework for the interviews. We use the terms "job" and "position" as these are commonly used in the literature of organisational socialisation. In our discussion we also refer to the concept of "role", the central point in parliamentary studies (Blomgren \& Rozenber 2015). As Andeweg argues, the concept is related to positions but not identical, the role expresses "[p]erceived expectations, personal motivations, and strategic calculations [which] are assumed to differentiate role from position" (Andeweg 2014, 1).

The study is intended to respond to the research gap that exists in the extant literature on national parliaments as organisations and workplaces. Despite the importance of national parliaments in society, they rarely feature as objects of studies in organisational theory and behaviour, which tend to focus on more numerous and traditional organisations, such as corporations, public organisations within the executive branch and associations. Parliamentary studies have focused on the dynamic roles of legislatures but research on the socialisation of newly elected MPs is scarce. The present study is intended to contribute to both academic fields.

\section{The parliament: The organisation, the members and the job}

\subsection{Parliament as a workplace}

Parliaments differ from more common workplaces in several ways, reflecting their uniqueness as organisations. In line with traditional wisdom, a parliament's primary role is to discuss and debate fundamental issues concerning the interests of society, make decisions in the form of law or other legislative decisions and scrutinise the work of the executive. In addition, in parliamentary systems, the government is backed by a parliamentary majority, which hence ties MPs to the executive branch of government. Moreover, in parliamentary systems, cabinet ministers are usually drawn from the ranks of senior MPs.

Parliamentary structure is multi-divisional and decentralised. Roughly, it can be described as consisting of:

- One or two parliamentary chambers (formal debating and decision-making).

- Standing committees (public policy-making, scrutiny role).

- Parliamentary party groups (policy coordination, interest articulation, debating).

- Offices of the parliament (operation of the parliament, assistance, leadership of the parliament, political- and non-political).

To a large extent, the work of parliaments is based on traditions, culture and norms, which differ from one general assembly to the next (Froman 1968; Hedlund 1984; Rogers \& Walters 2013). The Althingi, which is the backdrop to our study, has a long 
history, dating in its present form from 1845. It is one of the smallest parliaments in the world, with only 63 MPs and eight standing committees. The Althingi has been unicameral since 1991. Though cabinet ministers and the speaker of the Althingi do not serve on the standing committees, the rest of the members do. Accordingly, most MPs serve simultaneously on two standing committees (on average). This requires that they develop an expert knowledge of the issues that their committees deal with, together with a knowledge of other issues that they are required to vote on. In smaller parliamentary parties, MPs may find themselves stretched thin when it comes to covering all the standing committees and the issues they deal with. In larger parliamentary parties, more division of labour is possible, meaning that MPs do not need to become experts on all issues but can instead rely on the advice of their colleagues within their parliamentary party. Similarly, the expert pool within a parliamentary party group is also strengthened if there are cabinet ministers among its members.

During the last few decades, 'professionalisation' has taken place within parliaments on all continents. This is meant to increase legislative capacity and institutionalisation, as is reflected in more formalised parliamentary structure and activities (Saalfeld 1997; Rosenthal 1998; Moncrief 1994). This transformation has moved the job of an MP closer to a profession, a full-time professional job. Professionalisation has been measured by the so-called 'five S's': space, sessions, structure, staff, and salaries (Rosenthal 1998). Here, 'space' refers to office space for MPs and the parties represented in parliament (such space was either non-existent or very limited in the past); 'sessions' covers the development from temporary legislative sessions to sessions covering a large part of the year; 'structures' refers to changes in the number and structure of standing committees and assemblies' cameral structure; 'staff' refers to increases in the numbers of the parliamentary staff and, finally, 'salaries' refers to improved salary and pension arrangements for MPs.

The trend towards increasing professionalisation can be observed in Iceland. Already in the 1970s, being an MP in the Althingi had, for the most part, become a full-time professional job, instead of a part-time undertaking (Arter 2000). New buildings provided increased office space, a unicameral system had been established and the standing committee system was reorganised. All these efforts were aimed to increase the effectiveness and specialisation within the Althingi. The number of parliamentary staff has also grown, especially among professional staff members who work within several different departments. Furthermore, increased institutionalisation within the Althingi is reflected in a tighter regulatory framework for its committees, its standing orders and its code of ethics.

\subsection{The Political Parties}

MPs usually represent political parties, which are defined as organisations that participate in elections to acquire and exercise political power. These vary in their organisation, membership, ideology, etc. Political parties in Europe experienced fundamental changes in their operations in the last quarter of the 20th century (Scarrow \& Gezgor 2010; 
Whiteley 2011; Gallagher et al. 2011). As a general trend, mass-member parties, with their large membership base and complex governance structures, have been giving way to 'electoralist' parties, whose primary objective is to focus on election preparations by using professionally managed, state-of-the-art campaign techniques. The activities of electoralist parties are otherwise limited and organisationally "thin, maintaining a relatively skeletal existence" (Gunther \& Diamond 2003, 185). The criterion of whether a mass-member party has become electoralist is based not on the number of its members, but rather on whether large numbers of members actually play a role within the party, for example in formulating party policy and in elections to key positions within the party. In addition, in the closing decades of the 20th century, parties of another type were established: 'movement' parties. Such parties were frequently established by 'political entrepreneurs' and focused on a narrow range of policy issues or limited causes (Kitschelt 2006).

The Icelandic political party system developed into a four-party system; consisting of a right-of-centre conservative party (the Independence Party/Sjálfstæðisflokkur), a centre party (the Progressive Party/Framsóknarflokkur), a social democratic party (now the Social Democratic Alliance/Samfylkingin) and finally a leftist party (now the LeftGreen Movement/Vinstrihreyfingin grænt framboð). However, ever since 1983, five or more parties have always been represented in the Althingi. Until recent elections, the four main parties received the bulk of the votes in almost all elections. The election of 1987 was the exception, when other parties received 25\% of the vote. In the 2009 parliamentary elections, five parties won seats in the Althingi. In 2013 this number increased to six, then to seven in 2016, and to eight in the 2017 snap elections.

Electoral volatility results in fluctuations in the number of parliamentary seats allocated to the political parties, and also in the number of parties. This has also resulted in a very high turnover rate of MPs in the Althingi. After the 2009 parliamentary elections, $42.9 \%$ of MPs were new to the job, and the percentage of new MPs remained the same after the 2013 elections. After the 2016 elections it rose to $50.8 \%$ and was $30.2 \%$ after the elections a year later. Consequently, the average Icelandic MP has only a few years of experience in office. By gender, female MPs in 2017 had sat in the Althingi for 5.7 years on average, whereas the average for male MPs was 6.9 years. For new parties, this average was lower than for older parties (Handbók Alpingis 2019). Electoral volatility, and the outcomes of candidate selection processes within the political parties, go a long way towards explaining the high turnover rate of MPs in Iceland.

\subsection{The job of the MP}

Available studies portray the job of MPs as being highly demanding, complex, and dynamic (see, e.g., Rush 2001; Korris 2011; Weinberg 2012; Coghill, Lewis, \& Steinack 2012). It is partly based on formal rules, but also, to a large extent, on unwritten rules in the form of norms and work culture. According to Rush (2001), an MP has primarily a tripartite role which he or she needs to balance: a partisan role (i.e. supporting party policy in the legislative processes), a constituency role (in helping constituents with indi- 
vidual and collective problems) and a scrutiny role (which includes monitoring government by asking parliamentary questions and dealing with collective interests). Each role is charged with a variety of tasks worked at different forums. How MPs attend to their roles is influenced by their background (Wright 2010). It also depends on whether the MP is part of a government party or the opposition; and it is also likely to be affected by whether he or she belongs to a small or large party.

In Iceland, neither the Icelandic constitution nor the Standing Orders Act defines the roles of MPs, except for when it comes to their supervisory role. Nevertheless, the profession has some distinct features. First, MPs are, at least in theory, highly independent. They are to follow their own conscience, according to the constitution, and are not bound to obey orders from others, including their party leaders. Also, in the Icelandic context, there is no formal chain of command within parliamentary parties, nor between MPs and the office of the Althingi. Instead, an MP is the representative of a constituency, not a permanent employee of the party or parliament. An MP can only be 'fired' by the constituency in a new election. However, despite this independence, MPs face various constraints such as social pressures to follow the party line. Rules of procedures also limit MPs' discretion. As for job requirements, there are no formal ones, except for meeting the requirements of citizenship and minimum age. The 'hiring process' consists of the selection process within parties and the general elections.

Among the public, MPs are viewed as debaters and advocates, and even fixers (Rush \& Giddens 2011). But MPs must have command of the issues at hand, and they must also effectively communicate with voters and the public at large. The fact that parliament is not their sole place of work, as MPs also need to answer to their local constituencies as well as to the party at large, further complicates their job. Thus, MPs juggle multiple roles and tasks in various settings. This requires diverse skills as well as training. However, right from the outset, new MPs are faced with the fact that no objective criteria exist on what it takes to do a good job as an MP because of the unique nature of the work. Subsequently, new MPs may not even be sure about how they should prepare for the job, or whether job competence is achieved. All these factors differentiate the job of an MP from most professional jobs. The latter usually define a successful candidate as one who meets certain requirements, in terms of skills, education, and job training criteria which are deemed necessary to perform properly (Silvester et al. 2014).

As has been previously stated, 27 of the 63 MPs elected in 2013 were new to the job. They replaced MPs who had decided to retire from the Althingi (12), were not reselected by their parties during internal selection processes (6), or lost their seats in the parliamentary elections (9) (Handbók Alpingis 2014, 177).

\section{Methods}

We interviewed 16 of the 27 new MPs elected in the spring of 2013 to find out how they adapted to their new work roles; i.e. how they understood what was expected of them in the new role and learned to navigate the new working environment. All 27 new 
MPs received a request for interviews, but in the end 16 approved to participate. Details of the study had previously been made known to the speaker of the Althingi and other officials, and approval for the study sought from, and granted by, the Data Protection Authority. The participants came from all parties represented in the Althingi. Distribution by gender and age was consistent with that of the 27 new MPs.

The interviews were conducted primarily in the summer and fall of 2015, i.e. after the MPs had spent two years in office. They were conducted in person, in Icelandic, and lasted approximately two hours. The investigators began by explaining that the aim of the study was to understand how new MPs learned about and adjusted to their new job as members of parliament. The subjects were informed of who was involved in the study, the length and content of the interview and confidentiality issues. All participants signed a consent form.

The primary focus of the study was to investigate the preparation and adaptive accommodation stages of the organisational socialisation process. In line with this agen$\mathrm{da}$, the following questions: 'What were your expectations about the role before taking your seat in the Althingi?', 'How did you prepare for the role?', and 'Did you receive any support to help you prepare?' (anticipatory socialisation). Then they were asked to consider the period shortly after entering the Althingi and the first session 2013-2014 (accommodation). They were asked two critical incident questions (on critical incident technique, see Butterfield, Borgen, Amundson, \& Maglio 2005; Flanagan 1954) for each phase: 'Can you recall an incident that (1) was particularly important in helping you to understand what was required of you in your parliamentary role and (2) that you found particularly challenging or did not go as well as you had hoped?' For each of these six questions, the interviewer probed further by asking 'Can you describe what happened? What did you learn?' Finally, interviewers were asked: 'In retrospect, what were the primary obstacles you encountered in the adjustment process?' and 'Looking ahead, what would you want to change in order to become even more effective in your role?' (outcome of the socialisation process). The interviewees were asked about their background and all the interviews were recorded and transcribed in Icelandic.

\subsection{Other data gathering}

An unstructured interview was taken with an experienced MP at the time when the questions were formulated, the aim of this being partly to hear the MP's assessment of the appropriateness of the questions and to hear views on how new MPs adjusted to the workplace. The task at hand was also discussed, in a more general way, with people who had previously been MPs. Meetings were also held with the speaker of Althingi and senior parliamentary officials to inform them of the study, and to obtain information on the training workshops held for new MPs. We also relied on other sources of useful information, such as a manual prepared for MPs, Handbók. Alpingis, and the standing orders of the Althingi. All this information was useful both in the interviews and in working with the interview data. 


\subsection{Coding and analysis}

The interview material was analysed using template analysis (King 1998), which provides a flexible method of reclassifying data and identifying themes throughout the analysis process. Template analysis involves organising data into codes that are placed into a hierarchical 'template' where broad themes can be seen to encompass more specific findings. Depending on the research aims, higher order codes can either be pre-determined, by drawing on previous research or theories (Crabtree \& Miller 1992), or they can be entirely emergent and guided by the interview schedule. Once the higher order codes are identified, the researchers continue to examine the transcripts repeatedly to identify lower order codes that describe more specific and emergent findings.

The following two inductive codes were formed: Previous political experience (1) none (total of 11) (2) MP/substitute/assistant, in local politics (total of 5). Type of political party: (1) size (relative): Small (ten or less MPs, four parties), medium/large (more than ten MPs, two parties); (2) well-established (four parties) or new party (two parties) (3) Government party (two parties) /opposition party (four parties). ATLAS.ti qualitative data analysis software was used for coding and analysis.

\section{The Results}

This section describes the findings from semi-structured interviews with 16 first-term MPs elected in 2013. The structure of the section follows the key topic of the interviews: anticipatory socialisation, i.e. how the MPs prepared for the job and accommodation, and their experience of the first months. Finally, the section includes the interviewees' evaluation of the process after two years in parliament.

\subsection{The preparation}

How did the new MPs being interviewed prepare themselves for their new role as MPs, from the time they were elected until the Althingi was convened after their election? One MP stated:

I simply do not know how I could have prepared myself for work as an MP. There is no way of preparing for a job you know little or nothing about. (New MP without much political background.)

For some of the new MPs it came as a big surprise that they had been elected. Fluctuations in support in the weeks leading up to elections can be significant. This, and the fact that there usually are some uncertainties as to how constituency seats will be divided between the political parties, as well as to whom the supplemental seats will be allocated, means that some candidates remain uncertain about their election prospects until the vote count is complete. These uncertainties particularly affect candidates positioned low on the electoral roll and candidates of small and/or new parties. Additionally, some agree to put their names forward as party candidates without expecting to be elected. This was revealed in some of the interviews, where some MPs admitted that they had 
consented to lending their name to a party's candidate list, with casual commitment and without any real expectation of being elected. Citing an MP of a new party:

I went into this pretty much blindly and rather unexpectedly. I had never thought about it as a job for me. Standing as a candidate was not something I had planned at all. But I agreed to run assuming that being an MP was both demanding and enjoyable. (MP of a new party.)

The new MPs did nevertheless prepare for the job to some extent, though not in a formal manner. Thus, all said the election campaign had been helpful in preparing them for the job. During the campaign they formed expectations of what the job would be about. It brought them into contact with voters and made them familiar with the most pressing issues voiced by their constituents. The campaign also brought them into contact with other candidates, both from their own parties as well as other parties, enabling them to observe and learn from them. In some instances, friendships were formed.

Taking part in the election campaign was a valuable preparation, listening to the people I met at the meetings and finding out a bit what the priorities were that were being talked about there. So that was the preparation, I suppose, I was involved in at the time. (MP of an established party.)

The interviewees were asked what they considered a good prior background for the job. Two of the 16 MPs interviewed had previously been alternate members for a few weeks. Both said that experience had given them a sneak preview of how the Althingi operates, which was a good preparation. Likewise, those (total of 3) who had previously served on local municipal councils believed that experience helped them understand what was expected of them in their new roles as MPs. Participants also seemed to agree that experience with working with community groups and associations was helpful. One MP summed this up:

I think a background in local government makes a big difference. I think I can see a big difference between MPs who are starting off here, and have worked in local government and the others who have not, just in terms of how they understand the different roles of the national and local government, and how collaboration works. You also see that the people who have a lot of experience from the sports movement or from other types of associations, have advantages over those who lack such experience. The ones who have some difficulty in finding their way are those who have never taken part in any community work - because they do not know how to work in a group, how to debate issues, make compromises, and finally make decision. (MP from an established party.) 
When asked whether they thought a particular field of speciality, in terms of education, was an advantage for MPs, most of the MPs said no. However, the lawyers in the group believed they felt more at ease dealing with legal texts than the others.

\subsection{The first experience}

The new MPs gathered for the first time when the Althingi convened in the summer of 2013 for a short summer session. During these first days, they found out more about what awaited them in the new job. They came to know what standing committees they would serve on and got to know the staff and colleagues. They also attended a short introductory workshop, organised by the Althingi, where its organisation, main rules and procedures were explained. When the short summer session ended, the Althingi went into recess until the autumn. During the break, the new MPs continued familiarizing themselves with their new job.

For the most part, the interviewees agreed that they had been overwhelmed in the beginning; the exception being those who already had some experience as alternate MPs or staff members to politicians or parliamentary parties. The following describes how some MPs felt at first:

To begin with, I was completely lost. I couldn't find my way around the building; I didn't know where the general office was, or when chamber sessions were going to take place, or committee meetings, or when our parliamentary party was going to meet or what I was, generally, supposed to be doing in this workplace! And getting an understanding of all the various roles - it was all just very difficult. (MP of a new party.)

The following two excerpts also illustrate how unfamiliar everything seemed to the new MPs at first:

At the beginning it was as if I had just walked in to a big family confirmation party where I was only a distant relative and realised that all sorts of things had been happening in the family: an inheritance here, a divorce there, someone having an affair over there - without being able to understand what was what until much later. (MP of a new party.)

Suddenly I felt as if I were learning a new language in a new country! It was almost like starting to learn to read all over again. (MP of an established party.)

The new MPs were pleased with the introductory workshop for newcomers, but many felt it was too rudimentary and wished they had been given the option of attending 
more thorough courses, such as on the inner workings of the government, procedures and existing policies. Here are some examples:

The workshop was good as a way of getting key information, showing us how the parliament is structured and where to look for information. They also went over the formal side of things, like the dress code and other things like that. But the Althingi should have had a much more thorough and detailed preparation program for us. I suppose the parliamentary parties could also do more to help new MPs. (MP of a new party.)

Another MP said:

I think there is a need to be taught about the main features of the work of the legislature: the difference between acts of law and regulations, what is a bill and what is a parliamentary resolution. I should have had a week-long course, at least, on how the budget is prepared before I took my seat on the Budget Committee. I should not have to be an economist or a certified public accountant to play an active role on that committee. (MP from a new party.)

Another MP stressed the importance of getting better help with understanding the policy areas MPs were working on, arguing it should not be left to new MPs to figure everything out on their own, such as by reading through legislative proposals and searching for other supporting material. Organised visits to government agencies were welcomed, but not enough to master all the subjects at first. One MP put it this way:

In fact, something of this type is done: the committees go on visits to government bodies, but the sort of thing I have in mind is a course or a workshop where you would spend a whole week finding out how, say, the social insurance administration works. How is the system structured? What are the main challenges it faces? The way things are now we are just beginning to understand the things we are dealing with, close to the end of the parliamentary term, when some of us might be leaving the Althingi. (MP on the Welfare Committee.)

Finally, some MPs wished they had been given a better introduction into the finer details of the standing orders of the Althingi and its rules of procedure as this comment shows:

I need a better knowledge, and practice, in the Althingi's standing orders and procedural rules. I find myself learning the rules as they are 
being applied. Take the voting procedures for an example. I still do not understand the difference between voting on amendments to bills and voting on individual articles in bills. I find it all very complicated. (MP of an established party.)

As all these comments indicate, the MPs felt overloaded with all the information they had to quickly master. They also faced immediate demands to be up to speed on everything involving the job, while still lacking the necessary knowledge to meet these heavy demands and the scrutiny that comes with the job. Generally, the newcomers had to learn just by doing. Although, they had access to general assistance from the staff of the Althingi, and from the very small staff of the parliamentary parties, they felt they had to figure things out on their own. To help them learn faster, some new MPs sought the help and advice of other colleagues. One senior MP said:

An ex-minister and a former MP of my party, who is now ......, helped me in many ways. I had often met him in connection with local council work. I was also in contact with other former MPs, and they were all prepared to help me. They told me I could phone them at any time. (MP from an established party.)

Another MP said:

An MP from my party helped me a lot in my work in the committee. He was an incredibly good teacher. When things came up that I could not understand, he sat down with me and took the time that was needed. And he did not just go into the technical side; he explained all aspects of the case, including what implications it would have on my constituency. (MP of an established party.)

Interviewees reported that not only members of their own parties had helped them, but also experienced MPs from other parties. Such mentoring is, perhaps, especially important for MPs representing new parties. Here is one example:

$\mathrm{X}$ has an amazing amount of experience. You can always approach him and ask whether you have understood something fully. There is a lot of talk about bringing in new blood. But I thank God that he and $\mathrm{Y}$ were here in the house while I have been here. Because both are always ready to share their experience. I have always respected those willing to be a career MP, and I have the same passion for the job as they do. I regard $\mathrm{Y}$ as a good friend and teacher. He is a very capable MP. He has his own style and character, of course - and he is amusing! (MP of a new party.) 
The view is prevalent that new MPs should be given some slack, while they learn the roles of the job. There is also a sense of collegiality among MPs, which is demonstrated by the fact that they are willing to help each other, even though the harsh, political rhetoric may at times indicate the opposite. One senior MP put it this way:

You do not grill new MPs when they are giving their maiden speeches. This is an unwritten rule that applies across all parties. I appreciate this aspect of our work culture. (Senior MP of an established party.)

All the new MPs realised very early on that they needed to do a particularly good job on the standing committees because that is where bills are shaped and policies evolve. The principle of collegiality among MPs is also more at work within the standing committees, than, say, during open, public debates. This is demonstrated by the following comment:

The public sees only the bickering in the chamber, but what happens there is not representative of the work of the Althingi. It can be very rewarding to sit in one of the standing committees where in fact everyone is trying to row the boat in the same direction. That is where democracy works. The committee is approached by interested parties, and in fact not just interested parties but by all those who have an opinion and want to discuss it with the committee members. Also, most committee members also try to come well prepared to the meetings. Turning up to a meeting poorly prepared is not regarded as good form. (MP of an established party.)

\subsection{In hindsight - the first two years in office}

Interviewees were asked, after two years in office, to describe their experiences and role as MPs. They were asked to comment on the adjustment process as new MPs two years earlier. In particular, they were asked to identify the primary obstacles they encountered during this time. Responses varied. Most of the MPs considered their role and position challenging. It is possible that perceptions were somewhat coloured by which party individual MPs belonged to and whether it was in a majority or not. The following examples seem to indicate this:

As an MP I have a great deal of freedom, more than I expected, to work on my own ideas. Having good proposals approved is very rewarding - and I think I have been quite successful, measured on that scale. Overall, I think it is a creative and lively job, but it is demanding and can be very irritating, for example when they start filibustering. (MP of an established party.) 
This job is one of the most difficult and unpleasant that I have had, and I would be happy to stop tomorrow if it were politically responsible to do so. (MP from a new party.)

The MPs seemed to agree that adjusting to the job was an on-going learning process; not least because the job is highly dynamic and involves a variety of tasks that are different from one parliamentary session to another. Here are some examples:

I don't think there's any once-and-for-all learning process: you learn something from every issue, how to go about things, and you talk to your fellow party members about how to do things, and they give you practical advice, like reading the end of a bill first! (MP of an established party.)

My competence has grown slowly but steadily in this highly demanding job. For example, I feel there is a big difference between the way I am now compared with how I was in my first year. I have become an active participant. People are starting to listen to what I say. I am starting to be able to use my influence for the good. (MP of an established party.)

Part of the learning process was networking and creating connections based on mutual trust. A senior MP put it this way:

I was quick to connect with other people, and it is the same there as it is in other workplaces; there is chemistry between some people which leads to trust. This has nothing to do with what party you are in. You must give yourself time to build relationships with people you trust. In the beginning, my connections were mainly with others in my party, but after the first winter I began to form good working relationships with individuals from all the parliamentary parties, that is to say with people that I trusted. Therefore, it has been easy for me to get people from other parties to join me on legislative bills, etc.

The issue of trust often came up in the replies of the newcomers, who expressed the need to earn the trust of others, as well as the process of learning whom to trust. Here, it should be kept in mind that politics is a very competitive field. Political parties compete for the attention and support of voters. Similarly, MPs compete for the attention and support of party supporters, and of the public at large.

I think I was quite well prepared to do the traditional legislative work, but I'm not sure that I was well enough prepared to attend to the 


\section{STJÓRNMÁL \& \\ STJÓRNSÝSLA}

political side of things; I had never worked within the party before, of course. I had never been with these people; I did not know them previously. Maybe I had just been on nodding terms, but had never worked with them, except maybe in a very limited way. I did not grow up in the party like the others did. It takes time to gain the trust of people you do not know. (MP of an established party.)

There are people here whom I would not trust to run my shop while I took a holiday. But then again there are others here who I would make ministers straight away, irrespective of what parties they belong to. The individuals here are just so very different from each other! (MP of a new party.)

Obviously, not all the work that MPs do is confined within the walls of parliament. The most challenging aspect of the position of an MP seems to be dealing with being a public person and maintaining public support. There is no grace period for new MPs in the public sphere. Outside of parliament, they were expected, from the first day, to undertake responsibility for their work, and they often faced merciless criticism. Obviously, MPs need to adjust and cope with challenges they face in the position as MPs. This includes learning how to successfully utilize social media, deal with journalists, and getting their message across. For these purposes they need to advance/perfect their speaking skills and pay attention to looks and appearances. Dealing with these issues is an ongoing task for most MPs; some feel they are coping well while others are burdened by these pressures.

Finally, some MPs also felt that their lack of control over the Althingi's agenda and working hours was challenging and made it hard to anticipate workload and prepare for issues at hand. One of them put it this way:

I was surprised to see how massive the workload could be, for example in committee work. Often you are not finished doing everything you have to do before one in the morning. Then you must chair a meeting at eight o'clock the next morning. As a committee chairman, I was surprised to find how little support you get as an MP. I did not expect to have to resolve so many issues and to mug up on so many things. This leaves little time left for other things like putting together your own bills or do something like that - you get very little help with all of this. In fact, you are flat out, like on a running track, just to process all the stuff that is shovelled into the committee, and you do not have much time left over to work on anything else. (MP of an established party.) 


\section{Discussion and conclusion}

Our study was intended to provide insights into the adaptation of new members of parliament to a working environment that differs in many ways from that of more traditional workplaces. We used data from semi-structured interviews with 16 first-term members of the Icelandic parliament elected in 2013. The topic has been not been covered previously either in organisational studies or parliamentary research. Rush and Giddens' parliamentary socialisation model was used as a framework for our analysis.

\subsection{Who was involved in the newcomers' learning process?}

In Rush and Giddens' conceptualisation, a large number of agents, individuals and entities, both within and outside parliament, interact with newcomers and have the potential to influence the learning process and mastering of the new role. The study shows that no formal courses with the aim of facilitating the adaptation and learning process were offered before entering. Some had access to former parliamentarians as a source of guidance, either through their own party or earlier political collaboration. Inside parliament, support was provided by members of their own party, as well as others. Some interviewees mentioned senior MPs outside their party who, on their own initiative, assumed the role of informal mentors offering assistance and encouragement. Assistance from parliamentary staff was highly valued; however, this was evidently limited to nonpolitical assistance and advice such as informing the newcomers of formal procedures in the legislative process.

\subsection{The mechanism: How and where did the newcomers learn?}

The newcomers' political parties did not offer formal training for the new MPs. According to the interviewees, none of them prepared for the position of MP in an organised manner, e.g. by reading up on the parliament's functioning, rules of procedure, operation of standing committees or code of conduct. However, a prevalent view expressed was that the election campaign had been helpful in preparation for their role as MPs, both in terms of becoming better acquainted with voters' preferences and by creating networks. While the short introductory workshop offered by the Althingi's administration was useful, it was considered too limited to provide the necessary insight into the functioning of parliament, e.g. on the rules of procedure. Formal training within the policy areas of the standing committees that the newcomers joined was not available.

As might be expected, learning by doing and watching took place in many different forums within the parliament, in communication with colleagues in party meetings, meetings of standing committees, chamber debates, etc. Informal engagement in discussing and debating policy issues outside formal forums, in the corridors, coffee corners and the meal canteen also played an important role in the adaptation process.

\subsection{How did MPs view the learning experience and its outcome?}

In the first weeks a reality shock characterised the experience of most of the new MPs interviewed. Though this is a common experience for newcomers in all types of organi- 
sation, a case can be made for claiming that it was unusually strenuous for our interviewees. They had to rapidly master the rules, norms and behaviours of a complex job with no description, without guidance from a formal supervisor or any required former training. How they handled on-the-job training was their own responsibility. Several had no political experience before being elected. Especially outside parliament, they were expected, from the first day, to undertake responsibility for their work and face criticism by the media. Finally, the new parliamentarians found the work schedule challenging, being both unpredictable and intensive.

Two years into their term, the interviewees felt they were still learning and adapting to the rules and norms. One indicator of having achieved competence as a qualified MP that some recognised was when the colleagues began to turn to them for advice. Some parts of the workplace culture were considered advantageous for novice members, for example the consideration shown by senior members by their not being critical of their first contributions to chamber debates. They also noted differences in the response they received to their contributions to debates in the chamber, in the more collegial atmosphere of the standing committees, and in the way they were treated in the media.

Our data does not allow us to draw conclusions on what affected the interviewees' personal experiences as described above. Even though all thought the two years had been challenging, there were differences in how they experienced this adaptation. While some thought the time had been an invaluable life experience, others said the job was one of the worst they ever had. This negative attitude was however limited to only a very few interviewees from the new parties. Public debate and criticism of the government following the economic collapse of 2008 and the consequent emergence of new parliamentary parties brought into the legislature the view that the parliament needed to change fundamentally, both as regards it norms and its culture. However, for some of the members this did not happen (Margrét Tryggvadóttir 2014). With the proviso that our data was limited, it can be hypothesised that this negatively affected their experience.

\subsection{What factors affect parliamentary socialisation?}

Our study data does not allow us to go in depth into the contextual and contingent factors potentially influencing the organisational socialisation of the members of parliament. Four types of influencing factors can be defined: factors related to (1) the MPs' individual backgrounds, (2) the properties of the political parties, (3) the parliamentarians' roles, and (4) the parliament characteristics.

\subsubsection{Individual backgrounds}

Our study shows past political experience is a valuable resource for first-term MPs, for example participation in local government, having been an alternate MP, working within a political party and being active participants in local community groups, associations and clubs. Other working experience was not brought up. The interviewees did not consider any particular education to be important, though some mentioned legal studies.

Several other factors, not covered in this study, have been observed in the literature, 


\section{STJÓRNSÝSLA}

such as personal motivation and political ambitions (Schesinger 1966), political socialisation (Jennings \& Niemi 1968) and gender (Erikson \& Josefsson 2019).

\subsubsection{Properties of the political parties}

There are four properties of the political party that can affect the socialisation of an MP and are not covered in our study. The first two relate to socialisation outside the parliament, the others to work inside.

- Age. In our interviews we used a simple dichotomy for describing the "age" of the parties, characterising them as either well-established or new (see the definition in the methods section). Though parties in general do not provide formal training, as is mentioned in our study, certain other advantages may be entailed in being a member of an established party, e.g. as regards access to senior politicians who know the ins and outs of how the parliament works, and will provide informal assistance.

- Size. Thirdly, there is the factor of party "size". The number of MPs in a parliamentary party obviously influences newcomers' access to assistance from other parliamentarians within the same party. There is also a correlation between size and specialisation within the party and the intensity of policy issues an MP needs to cover.

- Party policy. This may include the aim of governmental reform, which includes parliament itself. It has already been mentioned that the new parties entering parliament had, as part of their agenda, the aim of changing how it operated; consequently, this had an impact on the work of the MPs regarding whether, or how, they adapted to the existing norms already mentioned in this chapter.

- Position in government, and whether a party's members are part of the governing majority or the minority, will affect MPs' roles as stated in the next section.

\subsubsection{MPs' role}

As previously stated, the role of MPs has been intensively covered in parliamentary studies (Blomgren \& Rozenberg 2015). One approach is to examine their formal position within the parliament. The workload and the pressure to learn can vary widely, depending, for example, on whether the new MP becomes a minister or the chair of the budget committee, or serves simply as a backbencher who does not hold any separate office. No comparison of different roles within parliament is included in the study.

\subsubsection{Characteristics of the parliament}

National assemblies differ in their specific characteristics from one country to another, and certain features can evidently affect the socialisation of new MPs. In international comparison, the Icelandic parliament is very small in terms of the number of MPs; this presumably affects the workplace culture, creating informal styles of communication 
and collaboration, as is indicated by the example from our study in which respondents mentioned having received help from informal mentors from other parties. The physical space is also confined, especially in the chamber. The Althingi uses a random system of allocation of seats in the chamber, resulting in mixing members from all parties. This is not addressed in the present study, but research has shown how the seating arrangement can affect the collegiality of members across the party lines (Saia 2018).

While we hope the findings of the study will provide valuable information on the adaptation by new MPs to their workplace, further research is needed to assess the impact of the factors mentioned above. In the light of increasing professionalisation among MPs and the trend towards treating parliament in the same way as any other workplace, as was revealed in a recent study of the Althingi as a working environment (Félagsvísindastofnun 2020), the practical and theoretical value of such studies is indisputable.

\section{Acknowledgements}

We thank all those who have been involved in this study. In addition to the authors, Professor Jo Silvester and Arndís Jónsdóttir, consultant and M.Sc. in occupational psychology, were part of the original team that developed the research approach. Mr. Gestur Páll Reynisson, MPA, assisted the research group in the interview process. The Social Research Institute of the University of Iceland helped with coding the interviews conducted for this study. The staff of the Althingi assisted us with practicalities in the implementation process. Finally, we especially want to thank the members of parliament who participated in the study for their time and valuable input.

\section{References}

Alpingi (2014). Handbók Alpingis 2013.

Alpingi (2019). Handbók Alpingis 2017.

Andeweg, R.B. (2014). "Roles in legislatures", in S. Martin, T. Saalfeld, and K.W. Strøm (eds.), The Oxford bandbook of legislative studies. Oxford: Oxford University Press.

Arter, D. (2000). "From a 'peasant parliament'to a 'professional parliament'? Change in the Icelandic Althingi", The Journal of Legislative Studies 6(2), 45-66.

Bauer, T.N., Bodner, T., Erdogan, B., Truxillo, D.M., and Tucker, J.S. (2007). "Newcomer adjustment during organizational socialization: a meta-analytic review of antecedents, outcomes, and methods", Journal of applied psychology 92(3), 707.

Bauer, T.N., Morrison, E.W., and Callister, R.R. (1998). "Organizational socialization: A review and directions for future research", Research in personnel and human resources management 16.

Bauer, T., Morrison, E., and Callister, R. (1998). "Organizational Socialization: A Review and Directions for Future Research”, Research in Personnel and Human Resources Management 16, 149-214.

Blomgren, M., and Rozenberg, O. (eds.) (2015). Parliamentary roles in modern legislatures. Routledge.

Butterfield, L.D., Borgen, W.A., Amundson, N.E., and Maglio, A.-S.T. (2005). "Fifty years of the critical incident technique: 1954-2004 and beyond", Qualitative research 5(4), 475-497.

Coghill, K., Lewis, C., and Steinack, K. (2012). "How should elected members learn parliamentary skills: an overview", Parliamentary Affairs 65(3), 505-519.

Cooper-Thomas, H. (2015). "Becoming an MP", The Psychologist (this volume) 28(5), 364-367.

Cooper-Thomas, H.D., and Anderson, N. (2006). "Organizational socialization: A new theoretical model and recommendations for future research and HRM practices in organizations", Journal of managerial psychology 21(5), 492-516. 


\section{STJÓRNSÝSLA}

Cooper-Thomas, H., and Silvester, J. (2014). Ideas and advice to accelerate the transition for new MPs entering New Zealand's House of Representatives. New Zealand: University of Auckland.

Crabtree, B.F., and Miller, W.L. (1992). "A template approach to text analysis: Developing and using codebooks", Doing qualitative research 3, 93-109.

Erikson, J., and Josefsson, C. (2019). “The legislature as a gendered workplace: Exploring members of parliament's experiences of working in the Swedish parliament”, International Political Science Review 40(2), 197-214.

Félagsvísindastofnun (2020). Könnun á vinnustaðamenningu Alpingis. Reykjavík: Félagsvísindastofnun.

Feldman, D.C. (1976). "A contingency theory of socialization", Administrative science quarterly 21(3), 433452.

Flanagan, J.C. (1954). "The critical incident technique”, Psychological bulletin 51(4), 327.

Froman, L.A. (1968). "Organization Theory and the Explanation of Important Characteristics of Congress", American Political Science Review 62(2), 518-526.

Gallagher, M., Laver, M., and Mair, P. (2011). Representative government in modern Europe. London: McGrawHill.

Gunther, R., and Diamond, L. (2003). "Species of political parties: A new typology", Party Politics 9(2), 167-199.

Hedlund, R.D. (1984). "Organizational attributes of legislatures: Structure, rules, norms, resources", Legislative Studies Quarterly 9(1), 51-121.

Jennings, M.K., and Niemi, R.G. (1968). “The transmission of political values from parent to child”, The American Political Science Review 62(1), 169-184.

Jones, G.R. (1986). "Socialization tactics, self-efficacy, and newcomers' adjustments to organizations", Academy of Management journal 29(2), 262-279.

King, N. (1998). "Template analysis", in G. Symon, and C. Cassell (eds.), Qualitative methods and analysis in organizational research: A practical guide (pp. 118-134). Sage Publications Ltd.

Kitschelt, H. (2006). "Movement parties", Handbook of party politics 1, 278-290.

Korris, M. (2011). A year in the life: From member of public to Member of Parliament: Interim briefing paper. London: Hansard Society.

Margrét Tryggvadóttir (2014). Útistöjur. Reykjavík: Hansen og synir.

Moncrief, G.F. (1994). "Professionalization and careerism in Canadian provincial assemblies: Comparison to US state legislatures", Legislative Studies Quarterly, 33-48.

Niemi, R.G., and Hepburn, M.A. (1995). "The rebirth of political socialization", Perspectives on Political Science 24(1), 7-16.

Rogers, R., and Walters, R. (2013). How Parliament Works (6th edition). Routledge.

Rosenthal, A. (1998). The decline of representative democracy: SAGE.

Rush, M. (2001). The role of the member of parliament since 1868: From gentlemen to players. Oxford: OUP Oxford.

Rush, M., and Giddings, P. (2011). "Parliamentary socialisation", Parliamentary Socialisation: Learning the Ropes or Determining Behaviour? (pp. 174-194). UK: Springer.

Saalfeld, T. (1997). "Professionalisation of parliamentary roles in germany: An aggregate-level analysis, 1949-94", The Journal of Legislative Studies 3(1), 32-54.

Saia, A. (2018). "Random interactions in the Chamber: Legislators' behavior and political distance", Journal of Public Economics 164, 225-240.

Saks, A.M., Uggerslev, K.L., and Fassina, N.E. (2007). "Socialization tactics and newcomer adjustment: A meta-analytic review and test of a model", Journal of vocational behavior 70(3), 413-446.

Scarrow, S.E., and Gezgor, B. (2010). "Declining memberships, changing members? European political party members in a new era", Party Politics 16(6), 823-843.

Schlesinger, J.A. (1966). Ambition and Politics: Political Careers in the United States. Chicago: Rand McNally.

Silvester, J., and Wyatt, M. (2015). "Developing strong and diverse political leaders", The Psychologist 28(5), 368-371. 
Van Maanen, J., and Schein, E.H. (1979). "Toward a theory of organizational socialization", in B.M. Staw (ed.), Research in organizational behavior (pp. 209-264). Greenwich, CT: JAI Press.

Weinberg, A. (2012). "Should the job of national politician carry a government health warning?-The impact of psychological strain on politicians", The psychology of politicians, 123-142.

Whiteley, P.F. (2011). "Is the party over? The decline of party activism and membership across the democratic world", Party Politics 17(1), 21-44.

Wright, T. (2010). "What are MPs for?”, The Political Quarterly 81(3), 298-308. 
